\title{
QVAST: a new Quantum GIS plugin for estimating volcanic susceptibility
}

\author{
S. Bartolini ${ }^{1}$, A. Cappello ${ }^{2}$, J. Martí ${ }^{1}$, and C. Del Negro ${ }^{2}$ \\ ${ }^{1}$ Group of volcanology, (SIMGEO-UB), Institute of Earth Sciences Jaume Almera, ICTJA-CSIC, Barcelona, Spain \\ ${ }^{2}$ Istituto Nazionale di Geofisica e Vulcanologia, Sezione di Catania, Osservatorio Etneo, Catania, Italy
}

Correspondence to: S. Bartolini (sbartolini@ictja.csic.es)

Received: 16 July 2013 - Published in Nat. Hazards Earth Syst. Sci. Discuss.: 22 August 2013

Revised: 18 October 2013 - Accepted: 23 October 2013 - Published: 27 November 2013

\begin{abstract}
One of the most important tasks of modern volcanology is the construction of hazard maps simulating different eruptive scenarios that can be used in risk-based decision making in land-use planning and emergency management. The first step in the quantitative assessment of volcanic hazards is the development of susceptibility maps (i.e., the spatial probability of a future vent opening given the past eruptive activity of a volcano). This challenging issue is generally tackled using probabilistic methods that use the calculation of a kernel function at each data location to estimate probability density functions (PDFs). The smoothness and the modeling ability of the kernel function are controlled by the smoothing parameter, also known as the bandwidth. Here we present a new tool, QVAST, part of the open-source geographic information system Quantum GIS, which is designed to create user-friendly quantitative assessments of volcanic susceptibility. QVAST allows the selection of an appropriate method for evaluating the bandwidth for the kernel function on the basis of the input parameters and the shapefile geometry, and can also evaluate the PDF with the Gaussian kernel. When different input data sets are available for the area, the total susceptibility map is obtained by assigning different weights to each of the PDFs, which are then combined via a weighted summation and modeled in a non-homogeneous Poisson process. The potential of QVAST, developed in a free and user-friendly environment, is here shown through its application in the volcanic fields of Lanzarote (Canary Islands) and La Garrotxa (NE Spain).
\end{abstract}

\section{Introduction}

Volcano susceptibility is defined as the spatial probability of vent opening (Martí and Felpeto, 2010) and constitutes one of the first steps in the assessment of volcanic hazards and the construction of hazard maps of eruptive products (e.g., lava flows, ash, and pyroclastic density currents). The exact site of a new eruption - a central vent or a vent located on the flanks of a stratovolcano, or at any other apparently randomly distributed point in a larger monogenetic volcanic field - is of critical importance in determining the potential outcome of an eruption. For the same eruption, different eruption scenarios and, consequently, different potential impacts are to be expected depending on the exact location of the vent and on the geographic and demographic characteristics of the area. Hence, evaluating where future eruptive vents are most likely to open greatly influences volcanic hazard assessment (Cappello et al., 2011a, b).

The exact path that the over-pressurized magma will take from its accumulation site to the earth's surface - and hence the site of any new vent - will be determined by geological structure and stress distribution inside the crust. We know that the energetic investment by the magma on this path will be the minimum and that it will be parallel to the trajectory of the main principal stress and normal to the minimum principal stress (Gudmundsson, 2008, 2012). However, we do not have any direct criteria that enable us to determine this route a priori since we lack detailed 3-D knowledge of the stress field of the area. In the long term it is possible to base some approaches on the location of previous eruptions and on the structural characteristics of the volcano or the volcanic area. On the other hand, in the short term it is also possible to take 
into account monitoring data from the volcanic field. Therefore, the estimation of the most probable vent site is not an impossible task and can be undertaken as part of volcanic hazard assessment. This is a less difficult task in stratovolcanoes for which good knowledge of past eruptive history exists and where real-time volcano monitoring is currently being performed. However, volcano susceptibility assessment is more complex in monogenetic volcanic fields, as has been shown by the recent eruption at El Hierro (Martí et al., 2013), where stress conditions may change from one eruption to another.

Published works in this field (Connor and Hill, 1995; Felpeto et al., 2007; Jaquet et al., 2008; Martí and Felpeto, 2010; Favalli et al., 2011; Connor et al., 2012; Cappello et al., 2012,2013 ) report the use of kernel density functions to evaluate susceptibility. However, this technique is based mainly on the assumption that new vents will not form far from existing ones (Martin et al., 2004; Jaquet et al., 2008). This is an a priori hypothesis for long-term hazard assessment, in which the use of volcano structural alignments (eruptive fissures, fractures, dykes) and the location of past centers of emission assumes implicitly that the general stress field has not changed significantly since the formation of these structures. Conversely, when dealing with short-term hazard assessment, monitoring data (Martí and Felpeto, 2010) - which provide important information regarding the evolution of magma migration and its ascent to the surface - play a major role in determining volcanic susceptibility.

A kernel function is a density function used to obtain the intensity of volcanic events. It is based on the distance from nearby volcanoes and a smoothing constant $h$ (Martin et al., 2004), which indicates the spatial probability that a new eruptive vent will form. A Gaussian kernel is a kernel function describing a normal distribution that is used in volcanology to estimate local volcanic event densities in volcanic fields (Martin et al., 2004; Connor et al., 2012; Cappello et al., 2012).

The aim of this work is to (i) analyze different approaches to evaluate the smoothing parameter $h$ (also known as the bandwidth), (ii) estimate for each approach the corresponding probably density function (PDF) and (iii) assess longterm spatial susceptibility in monogenetic volcanic fields. We describe here a new user-friendly plugin known as QVAST (QGIS for VolcAnic SuscepTibility) for the free geographic information system Quantum GIS (QGIS), which can make these calculations and help users to choose the best option in each particular case (Fig. 1). We describe the QVAST interface step by step via two different applications: the first in Lanzarote (Canary Islands, Spain) and the second in La Garrotxa (NE Spain). These two case studies show QVAST's great flexibility and its ability to identify the most likely zones to host new eruptions in monogenetic volcanic fields.

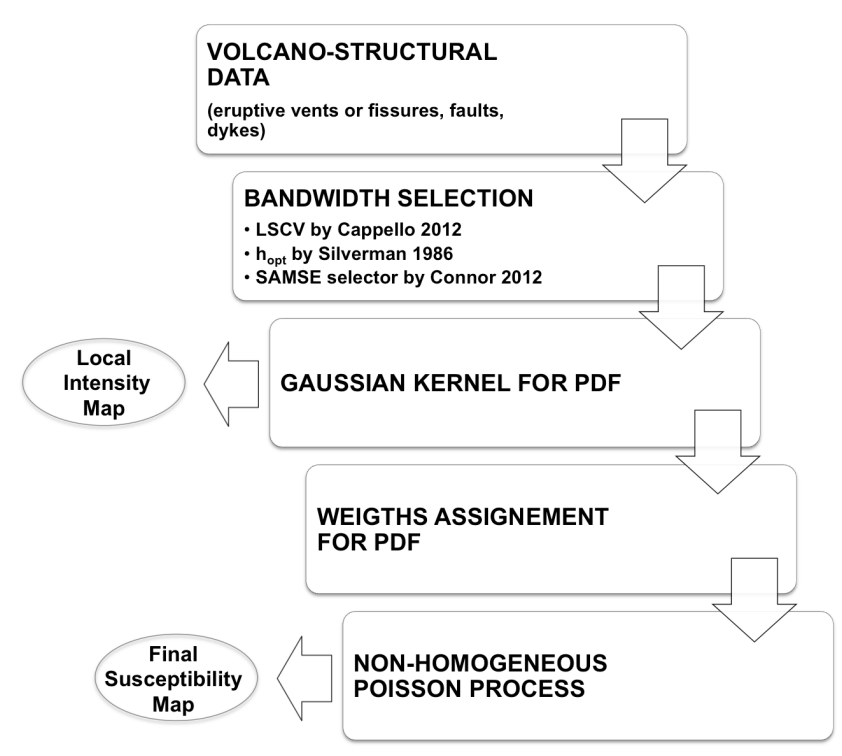

Fig. 1. Flowchart showing the main steps available in QVAST.

\section{Optimal bandwidth in kernel density estimation}

The probability distribution in a kernel technique is strongly influenced by a smoothing parameter or bandwidth, which determines how probabilities are distributed in terms of the distance from the volcanic structures or vents. The smoothness of the kernel density estimate is evident compared to the discreteness of the histogram, as bin width of a histogram, for continuous random variables (Scott, 1979). An optimal smoothing bandwidth is based on the clustering behavior of the volcanic structures and varies proportionally with the volcanic field size and vent density. Indeed, narrow bandwidths accentuate densities near the locations of past events. Conversely, broad bandwidths may oversmooth the density estimate, resulting in unreasonably low density estimates near clusters of past events, or overestimate densities at greater distances from past events. In a Gaussian kernel function, the bandwidth is equivalent to the variance of the kernel (Connor et al., 2012).

In volcanic hazard applications, the choice of the optimal bandwidth is difficult and depends on the field size and degree of cluster determining the probability distribution at distance from volcanic structures or eruptive vents.

QVAST provides a number of different methods for estimating the optimal bandwidths. The least square crossvalidation (LSCV - Cappello et al., 2012) is made available for the volcanic structures with linear geometries (e.g., dykes, eruptive fissures, faults), and three methods are provided for the eruptive vents: the LSCV, the $\hat{h}$ score (Silverman, 1986) and the sum of asymptotic mean squared error (SAMSE) selector $H$ (Connor et al., 2012).

An exhaustive description of each of these methods is hereinafter provided. 


\subsection{Least square cross-validation (Cappello et al., 2012)}

Least square cross-validation (LSCV) is a procedure that uses an iterative approach to determine the optimal bandwidth for fixed kernel functions. Initially proposed by Rudemo (1982) and Bowman (1984), the LSCV uses the minimization of the integrated square error between the estimated distribution and the true distribution.

In our QGIS plugin, we used the version proposed by Worton (1995), defined as

$$
\begin{aligned}
\operatorname{LSCV}_{h} & =\frac{1}{\pi h^{2} n}+\frac{1}{4 \pi h^{2} n^{2}} \\
& \times \sum_{i=1}^{n} \sum_{j=1}^{n}\left(\exp \left[\frac{-d_{i j}^{2}}{4 h^{2}}\right]-4 \exp \left[\frac{-d_{i j}^{2}}{2 h^{2}}\right]\right),
\end{aligned}
$$

where $h$ is the smoothing factor, $n$ the total number of historical data and $d_{i j}$ the Euclidean distance between the $i$ th and the $j$ th points, when dealing with eruptive vents.

Conversely, if historical data consist of broken lines containing a number of linear segments, QVAST uses a modified version of LSCV (Cappello et al., 2012; Becerril et al., 2013; Cappello et al., 2013), where $d_{i j}$ is the "minimax distance" (i.e., the minimum value of the maximum distances between each end point of the $i$ th volcanic structure and all the end points of the $j$ th volcanic structure).

\subsection{The $h_{\text {opt }}$ score (Silverman, 1986)}

The Silverman method determines the optimal bandwidth $h$ based on the assumption that the location of the vent opening is a random variable. The generalization of the Silverman's rule of thumb (Silverman, 1986) in the multivariate case is as follows (Scott, 1992; Härdle et al., 2004):

$\hat{h}=n^{1 /(d+4)} \hat{\sigma}$.

In the bivariate case $d=2, n$ is the length of the samples ( $x$ and $y$ are the Cartesian coordinates), and $\hat{\sigma}$ is the standard deviation. Thus, we obtain

$\hat{h}=n^{1 / 6} \sqrt{\frac{\sigma_{x}^{2}+\sigma_{y}^{2}}{2}}$,

where $\sigma_{x}$ and $\sigma_{y}$ are the standard deviations of the $x$ and $y$ coordinates, respectively.

\subsection{The sum of asymptotic mean squared error selector (Connor et al., 2012)}

The pilot bandwidth selector is a modified asymptotic mean integrated squared error (AMISE) method developed by Duong and Hazelton (2003) to evaluate the optimal bandwidth in kernel density estimation.

Despite their mathematical complexity, SAMSE bivariate bandwidth selectors can help find optimal bandwidths using actual data locations, and so remove subjectivity from the process (Connor et al., 2012). In Duong and Hazelton (2003), the bivariate kernel density is defined by

$\hat{f}(\boldsymbol{x} ; \mathbf{H})=n^{-1} \sum_{i=1}^{n} K_{\mathbf{H}}\left(\mathbf{x}-\mathbf{X}_{i}\right)$,

where $n$ is the sample size, $\boldsymbol{x}=\left(x_{1}, x_{2}\right)^{T}, \mathbf{X}_{i}=\left(X_{i 1}, X_{i 2}\right)^{T}$, for $i=1,2, \ldots, n$, and $K$ is the bivariate kernel that depends on $\mathbf{H}$, the bandwidth matrix that is symmetric and positive definite. To measure the performance of $\hat{f}$, a SAMSE pilot selector is used, which is simpler and more parsimonious than the AMISE selectors.

The SAMSE selector is freely available within the "ks" package of the R Project for Statistical Computing (Duong, 2007; Hornik, 2009) and can be expressed as follows:

$H=H p i\left(\boldsymbol{x}, n\right.$ stage, pilot $=^{\prime}$ samse ${ }^{\prime}$, pre $=^{\prime}$ sphere' $)$,

where $\boldsymbol{x}$ is a vector or matrix of data (vents), $n$ stage is the number of stages in the plugin bandwidth selector, pilot is the pilot estimation, and "pre" concerns the pre-transformations.

The spatial density estimates are based on the distribution of past events within a volcanic field and the time period under consideration, and can be used as the basis for estimating the probability of the opening of new vents within a region. Connor et al. (2012) define an event as the opening of a new vent at a new location during a new episode of volcanic activity.

The optimal bandwidth matrix obtained using Eq. (5) represents smoothing in $\mathrm{E}-\mathrm{W}$ and $\mathrm{N}-\mathrm{S}$ directions, the upper left and lower right diagonal elements, respectively.

\section{Kernel density estimation}

Kernel density estimation is a well-known, non-parametric approach to the estimation of probability density functions using a finite number of samples. The shape of kernel function - be it Cauchy kernel (Martin et al., 2004), Epanechnikov kernel (Lutz and Gutmann, 1995) or Gaussian kernel (Connor and Hill, 1995) - is important in probability calculations, even if it is less relevant than other parameters (Connor and Hill, 1995; Lutz and Gutmann, 1995).

In the general case, if $\boldsymbol{X}_{i}$ denotes samples of size $n$, then the kernel density estimate of $\lambda$ in the point $x$ is given by

$\lambda(x)=\frac{1}{n} \sum_{i=1}^{n} K_{h}\left(x, \boldsymbol{X}_{i}\right)$,

where $K_{h}$ is a kernel function with bandwidth $h$, satisfying the condition that $\int K_{h}(x, \cdot) \mathrm{d} x=1$ to ensure that $\lambda(x)$ is a density. In the Gaussian formulation,

$\lambda(x)=\frac{1}{2 \pi n h^{2}} \sum_{i=1}^{n} \exp \left(-\frac{d_{i}^{2}}{2 h^{2}}\right)$. 


\section{Interface and tools of QVAST}

Available open-source desktop GISs have notable differences in quality and performance (Sherman, 2008; Chen et al., 2010). Quantum GIS (QGIS) is a free, open-source and cross-platform software, distributed at www.QGIS.org. It includes all of the common GIS functions and features and possesses an intuitive and user-friendly interface. One of the great advantages of QGIS is the availability of plugins from official and third-party repositories that provide a large number of additional functions. These features make QGIS the most suitable software for our plugin.

QVAST is developed in Python script, an interpreted, general-purpose, high-level programming language, whose codes can be packaged into stand-alone executable programs (using sub-process calls to $\mathrm{R}$ ) and $\mathrm{C}++$ codes. A graphical user interface (GUI) is available to provide users with a dynamic graphical window in QGIS.

QVAST includes different methods for choosing the optimal value for the bandwidth, which depends on the size of the volcanic field and the degree of clustering in the available data. The PDF is constructed using a kernel density estimator, which is a function centered at each data sample location that exerts an influence on the surrounding region (Diggle, 1985). It is employed to estimate how the density of new vent openings varies across a study area in accordance with the distribution of past eruptions and the bandwidth. Different types of kernels can be used to describe the spatial density, e.g., the Cauchy (Martin et al., 2004), Epanechnikov (Lutz and Gutmann, 1995), Gaussian (Connor and Hill, 1995), or elliptical (Kiyosugi et al., 2010) kernels. Here we use the Gaussian kernel, which responds well to the clustering phenomena commonly observed in volcanic distributions (Weller et al., 2006).

Long-term spatial susceptibility is obtained through a nonhomogeneous Poisson process (NHPP), where the PDFs and their relative weights are combined through a weighted sum. QVAST allows users to assign different weights to each of the PDFs depending on the relevance and reliability of data sets. Once the user has installed the plugin in the QGIS plugins folder, a new option called "Volcano" appears in the QGIS menu bar where the QVAST model is installed.

The QVAST structure consists of three main modules (Fig. 2):

1. Estimation of the optimal bandwidth starting from different geometric layers (points and polylines);

2. Evaluation of the Gaussian kernel and generation of the PDF in the volcanic area under study;

3. Calculation of the susceptibility map from one or more PDFs. In this latter case, QVAST allows users to assign different weights to each layer.
The first window that appears after launching the plugin is the evaluation of the bandwidth. A drop-down menu contains the shapefile layers added in the "Layers" menu in the QGIS project. To estimate the optimal bandwidth in case of a group of sample points (e.g., eruptive vents), QVAST offers three different methods: LSCV, the $\hat{h}$ score and the SAMSE selector $H$. If the GIS layer consists of linear volcanic structures (e.g., dykes, eruptive fissures, or faults), only the LSCV score can be used. Otherwise, the plugin allows the user to introduce the optimal value for the bandwidth by hand (if known) and continue directly to the construction of the PDF.

Once the layer and the method for evaluating the bandwidth have been selected, the value of the smoothing parameter is calculated using the "CALCULATE BANDWIDTH" button.

The second window enables the PDF with the Gaussian kernel to be evaluated using the calculated optimal bandwidth. To evaluate the Gaussian kernel on the selected layer, QVAST needs the following input parameters: the surface area on which the calculation is to be performed (raster layer), the grid resolution (which should be clearly smaller than the size of the volcanic area under study), the bandwidth value, the output name, and the output path where the results are to be saved. The surface area can be less than the entire digital elevation model (DEM) if the user is only interested in a particular area. The result of the Gaussian kernel is a PDF in GeoTIFF raster format, which is automatically added as a new layer to the active QGIS project. The results show the distribution of the PDF in the volcanic area related to the input layer selected.

The third window enables simultaneously considering different layers to which different weights can be assigned and thus calculate the final susceptibility map. Once the grid size and the weight for each PDF have been defined, QVAST calculates the weighted sum and evaluates the final raster map that represents the spatial susceptibility. The map is presented in a GeoTIFF raster format and is added to the layer.

Hence, the steps needed to obtain the final susceptibility can be summarized as follows (Fig. 1):

1. Gathering of all volcano structural data available;

2. Optimal bandwidth selection using different methods;

3. Application of the Gaussian kernel to obtain the PDF;

4. Assignment of a relative weight to each PDF;

5. Creation of the susceptibility map with an NHPP.

The functionality and flexibility provided by QVAST have been demonstrated in Lanzarote and La Garrotxa volcanic fields. Different methods were used to identify the optimal bandwidth, and different results were obtained when different weights to the PDFs were assigned. 

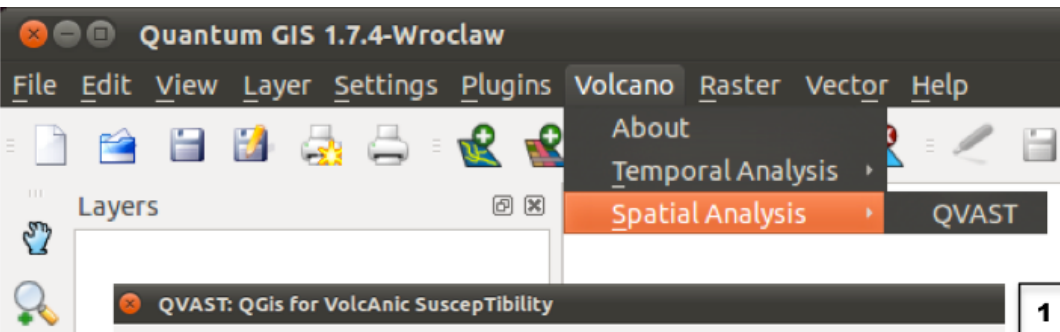

BANDWIDTHSELECTION GAUSSIAN KERNEL FINAL SUSCEPTIBILITYMAP

- LINEAR VOLCANIC STRUCTURES SERUPTIVE VENTS

(dykes, eruptive fissure or foults)

- ERUPTIVE VENTS

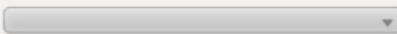

METHODS:

LSCV by Cappello et al. (2012)

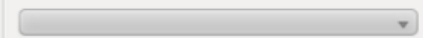

METHODS:

h_opt score by Silverman (1986)

SAMSE selector by Connor et al. (2012)

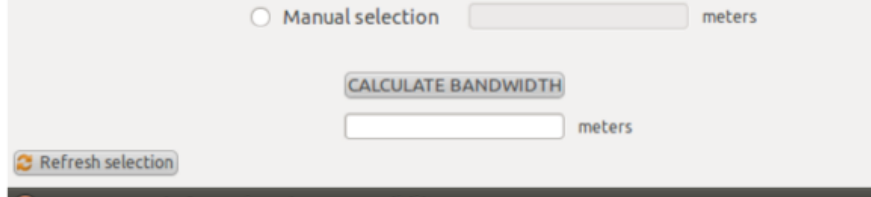

Q QVAST: QGis for VolcAnic Susceptibility

BANDWIDTHSELECTION GAUSSIAN KERNEL FINAL SUSCEPTIBILITYMAP Select DEM

LAYER EXTENT

Change values if you want reduce the area of the kernel anlysis

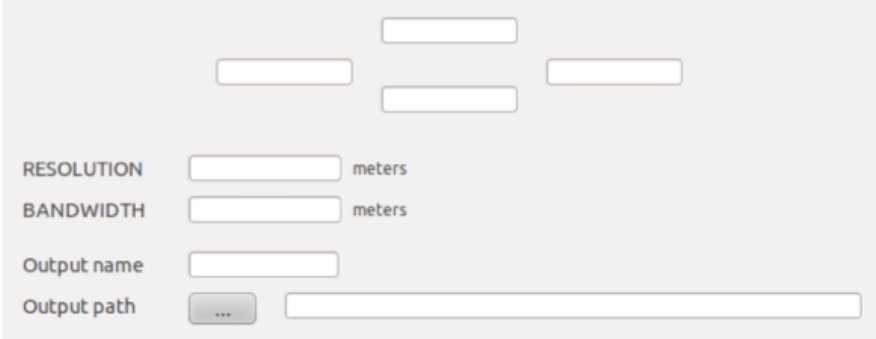

QVAST: QGis for VolcAnic SuscepTibility

BANDWIDTHSELECTION GAUSSIAN KERNEL FINAL SUSCEPTIBILITY MAP

Select PDF layers to evaluate the final susceptibility map

Layers

Weight
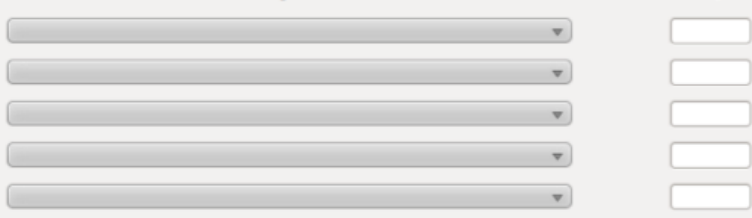

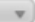




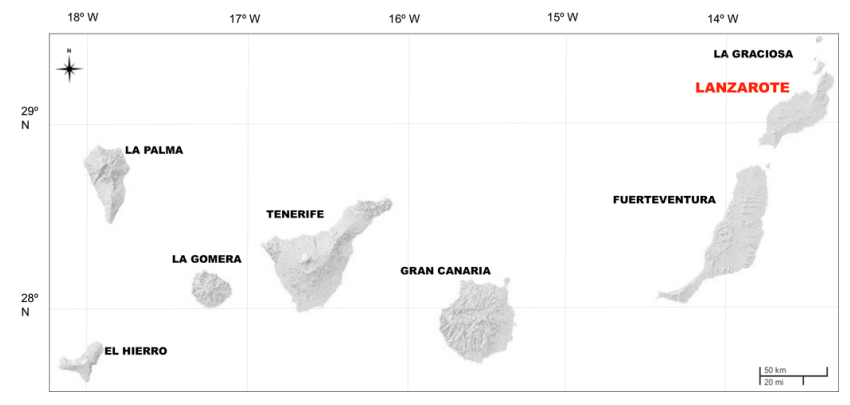

Fig. 3. Geographical setting of the Canary Islands.

\section{Applying QVAST: Lanzarote (Canary Islands, Spain) and La Garrotxa (NE Spain)}

\subsection{Lanzarote: geological context}

Lanzarote lies in the northeast of the Canary Islands archipelago (Fig. 3). It forms the emergent part of the socalled East Canary Ridge (ECR), a NNE-SSW linear volcanic structure located on atypical oceanic crust, at least $11 \mathrm{~km}$ thick (Banda et al., 1981), lying between the continental rise and the Canary Basin.

The geological evolution of Lanzarote involves two main stages: the first pre-erosional during the Miocene-Pliocene and the second - divided into two periods of volcanic activity - post-erosional during the Quaternary (Marinoni and Pasquaré, 1994).

Sub-aerial volcanic activity has been almost continuous during the past $20 \mathrm{Myr}$ and reveals that these islands are part of a sector of the lithosphere in which the thermal and dynamic anomalies that lead to the production and ascent of alkaline basaltic magmas have persisted for an exceptionally long period (Coello et al., 1992; Blanco-Montenegro et al., 2005).

In historical times eruptions on Lanzarote took place during the 18th and 19th centuries. The eruption between 1730 and 1736 was one of the earth's biggest ever historical eruptions. A large number of volcanic cones were formed along an around $15 \mathrm{~km}$ long fissure. During the eruption $3-5 \mathrm{~km}^{3}$ of lava were emitted, covering an area of approximately $200 \mathrm{~km}^{2}$ (Carracedo et al., 1992; Felpeto et al., 2001).

The structural evolution results from a complex interaction between the magmatism and both the regional stress field and the local stress field generated during the growth of the island itself. Hence, the present structural architecture is the result of a complex magmatic and tectonic evolution characterized by variations in the stress field that have been at work from the Miocene to the present day (Camacho et al., 1991).

\subsection{La Garrotxa: geological context}

The Catalan Volcanic Zone (CVZ, NE Iberian Peninsula) is one of the alkaline Quaternary volcanic provinces that form

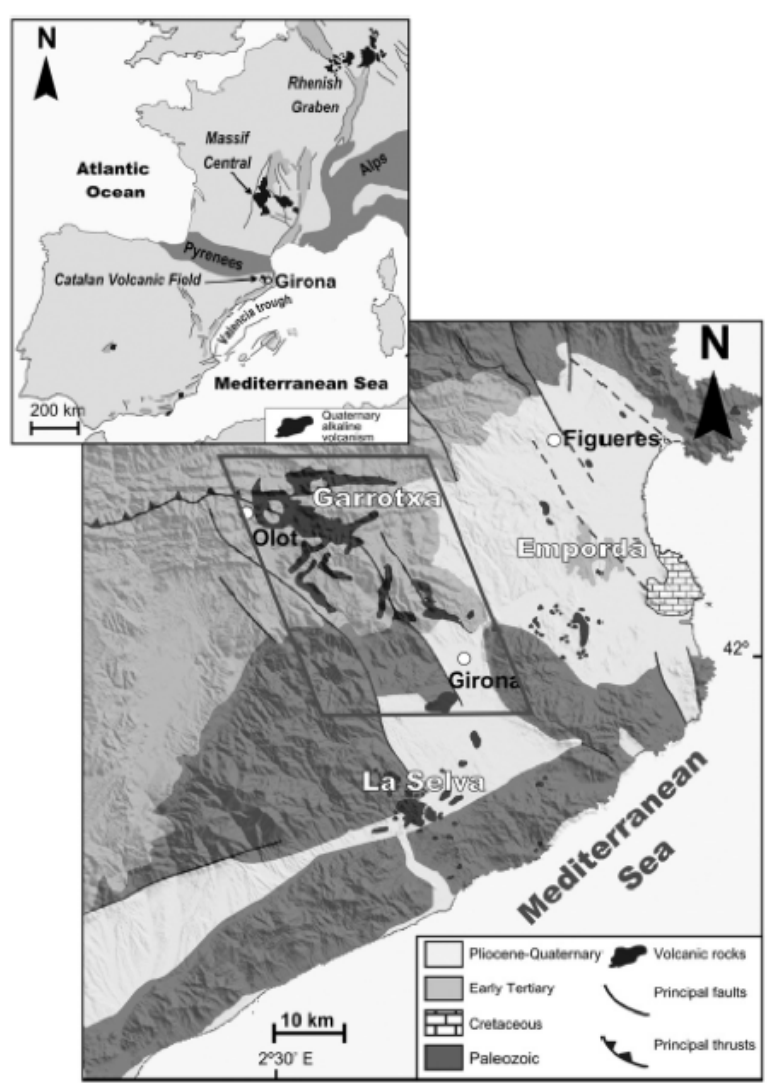

Fig. 4. Geographical and geological settings of the La Garrotxa volcanic field (Martí et al., 2011).

part of the European rift system (Fig. 4). The age of its volcanism has not yet been fully defined. Available data indicate that volcanic activity started over $12 \mathrm{Ma}$ ago and continued up to the beginning of the Holocene. Despite being significant in both extension and volume, this volcanism whose eruptions continued up to the Holocene - is poorly known in comparison to the contemporaneous alkaline volcanism in other parts of western and central Europe. Volcanism in the CVZ lies predominantly in a NW-SE direction corresponding to the graben system present in the area. Various vents in the area can be aligned in the same NW-SE direction in parallel to the local fault systems. The volcanism younger than $0.5 \mathrm{Ma}$ is mostly concentrated in an area of about $100 \mathrm{~km}^{2}$ located between the cities of Olot and Girona. This basaltic volcanic field exhibits scoria cones, lava flows, tuff rings, and maars. Magmatic eruptions range from Hawaiian to violent Strombolian. Phreatomagmatism is also common and has contributed to the construction of more than half of the region's volcanic edifices. It is frequently associated with Strombolian activity but has also acted independently, thereby giving rise to a large variety of different types of eruptive sequences (Martí et al., 2011). 


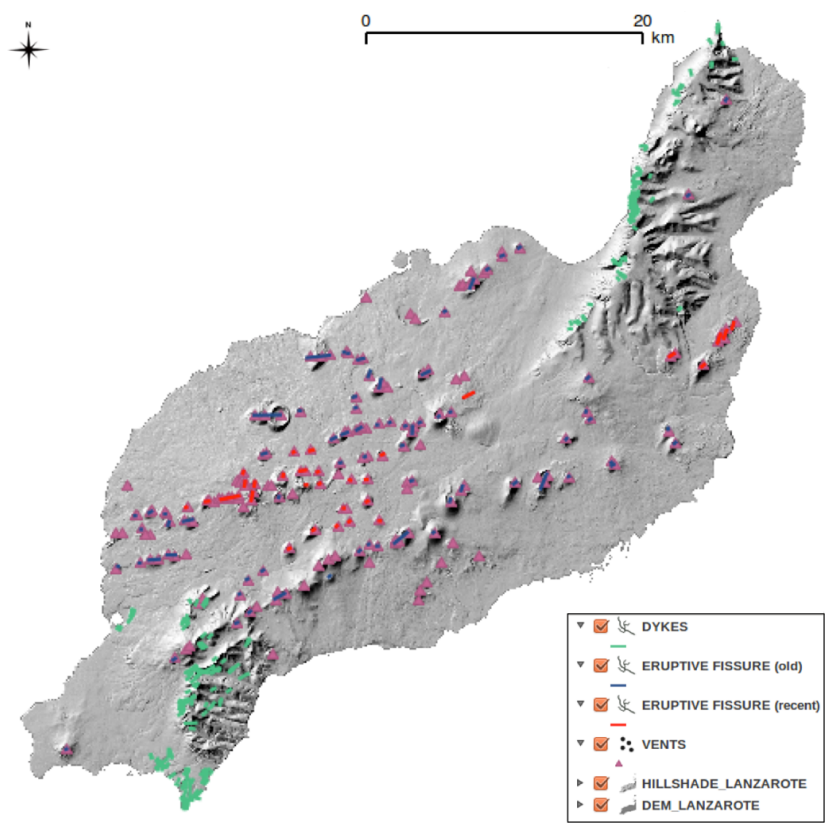

Fig. 5. Main volcano structural data (dykes, vent alignments and emission centers) used to build the susceptibility map of Lanzarote. The topographic base is $25 \mathrm{~m}$ resolution DEM.

\subsection{Data sets and bandwidth estimation}

DEMs created by the Instituto Geográfico Nacional (IGN) for Lanzarote and by the Institut Cartogràtic de Catalunya (ICC) for La Garrotxa with a cell size of $25 \times 25 \mathrm{~m}$ were used in these analyses. Volcano structural data were retrieved by the Instituto Geológico y Minero de España (IGME, 1988) for Lanzarote and by the Institut Geológic de Catalunya (IGC, 2007) for la Garrotxa.

Volcanic susceptibility was estimated by studying separately all structural data in order to identify different data sets that could be used for the probabilistic analysis. Using the available literature and geological maps, we were able to identify vent locations, vent alignments, and dykes.

\subsubsection{Application to Lanzarote}

Volcanic structures on Lanzarote are shown in Fig. 5. Specifically, we considered 256 dykes and two layers of vent alignments containing 75 older vent alignments and 30 more recent vent alignments, formed during the Holocene. Since both dykes and vent alignments can be represented as polyline shapefiles, QVAST used the LSCV method to calculate the optimal values for the bandwidth, which were found to be the following:

- $351 \mathrm{~m}$ for dykes,

- $3000 \mathrm{~m}$ for the oldest vent alignments,

- $2304 \mathrm{~m}$ for the most recent vent alignments.

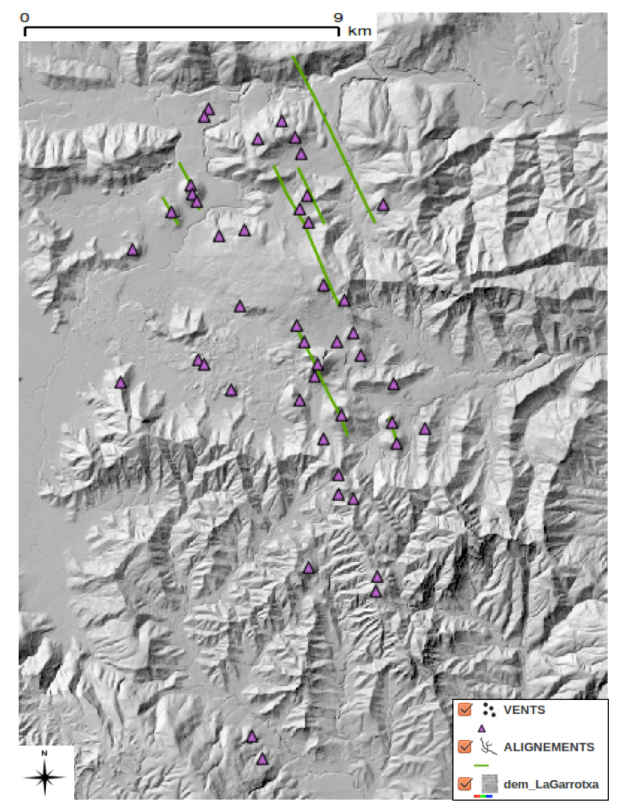

Fig. 6. Main volcano structural data (dykes, vent alignments and emission centers) used to build the susceptibility map of La Garrotxa. The topographic base is $25 \mathrm{~m}$ resolution DEM.

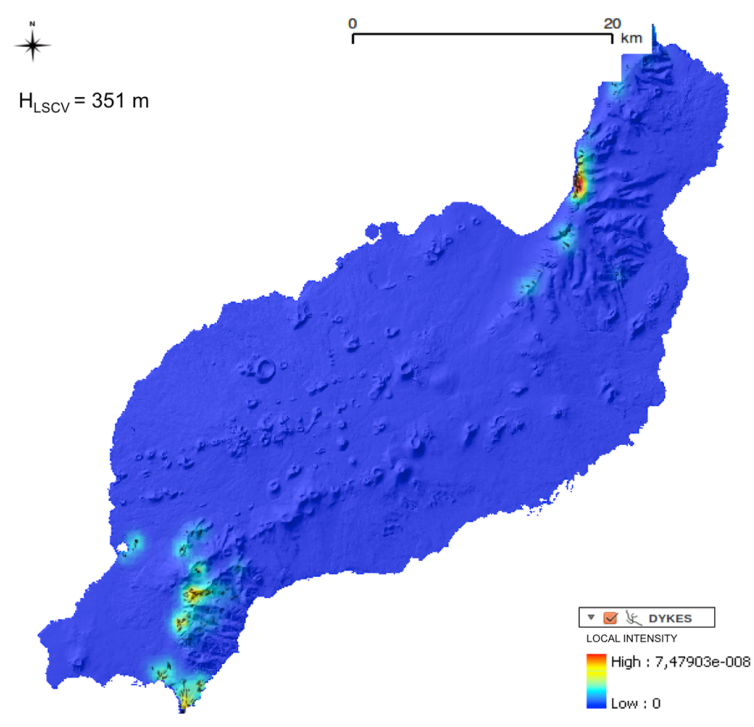

Fig. 7. PDF of Lanzarote dykes calculated with the Gaussian kernel using a bandwidth of $351 \mathrm{~m}$.

As well, we identified a total of 187 emission centers (Quaternary pyroclastic cones and eruptive vents), most of which are distributed in the central part of the island in a NE-SW direction (Marinoni and Pasquaré, 1994).

The evaluation of the bandwidth for the vent locations was performed using the three methods available in QVAST and the following results were obtained: (i) $333 \mathrm{~m}$ with the LSCV method, (ii) $3844 \mathrm{~m}$ with Silverman's method, and (iii) $3934 \mathrm{~m}$ with the SAMSE selector. 

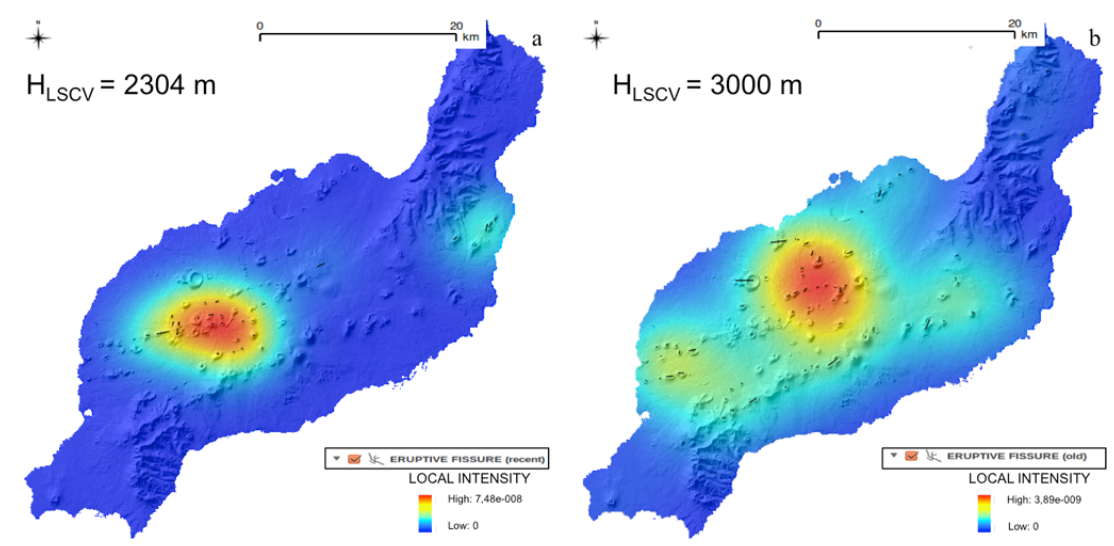

Fig. 8. PDFs calculated with the Gaussian kernel for the most recent (a) and the oldest (b) vent alignments of Lanzarote.
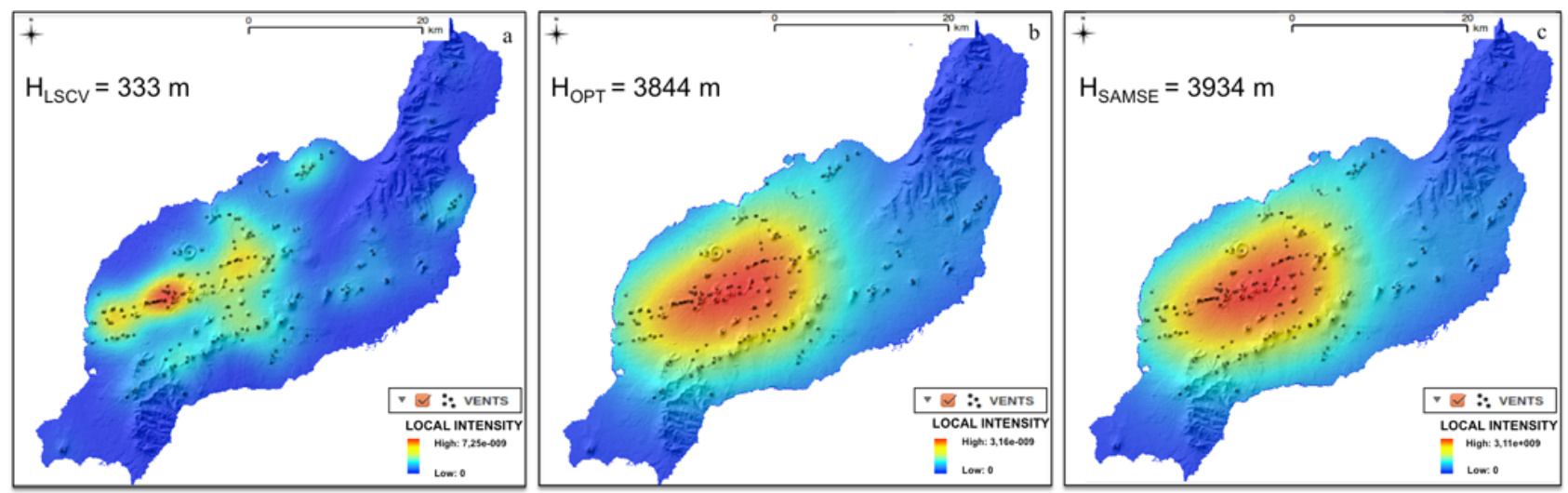

Fig. 9. PDFs of Lanzarote emission centers calculated with the Gaussian kernel using different bandwidths: $333 \mathrm{~m}$ as computed by the LSCV method (a), $3844 \mathrm{~m}$ as by the $h_{\mathrm{opt}}$ score (b), and $3934 \mathrm{~m}$ as by the SAMSE selector (c).

The PDFs for each layer evaluated using the Gaussian kernel and a $500 \mathrm{~m}$ spaced grid are shown for dykes in Fig. 7, for vent alignments in Fig. 8, and for emission centers in Fig. 9.

Given that the PDF generated using the bandwidth obtained with the LSCV seems to provide the best reflection of the current clustering of the emission centers observed, we decided to use this method for the final susceptibility map.

\subsubsection{Application to La Garrotxa}

Volcanic structures in La Garrotxa are shown in Fig. 6. Specifically, we considered vent alignments and emission centers.

Given that the vent alignments can be represented as polyline shapefiles, QVAST used the LSCV method to calculate the optimal value for the bandwidth, which was found to be $4012 \mathrm{~m}$.

In addition, we identified a total of 45 emission centers aligned in a NW-SE direction, parallel to the fault systems (Martí et al., 2011).
As on Lanzarote, the evaluation of the bandwidth for the vent locations was performed using the three methods available in QVAST, which gave the following results: (i) $2002 \mathrm{~m}$ with the LSCV method, (ii) $1774 \mathrm{~m}$ with Silverman's method, and (iii) $1567 \mathrm{~m}$ with the SAMSE selector.

The PDFs for each layer evaluated using the Gaussian kernel and a $500 \mathrm{~m}$ spaced grid are shown for vent alignments in Fig. 10 and for emission centers in Fig. 11.

The PDFs obtained for the vent locations using different bandwidth values generate similar local intensity results. Taking into account isolated vents, we decided to use Silverman's method for the final susceptibility map since it seems to provide the best reflection of the degree of clustering currently observed.

\subsection{Susceptibility map}

The spatial probability of future vent openings is obtained by applying an NHPP to each potential vent $(x, y)$ as follows:

$\operatorname{susc}(x, y)=1-\exp (-\Lambda(x, y) \Delta x \Delta y)$, 


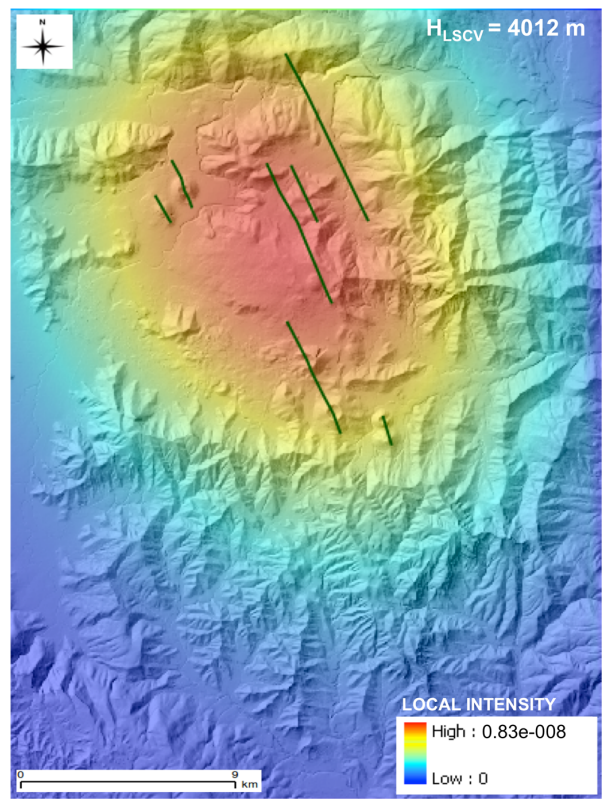

Fig. 10. PDFs calculated with the Gaussian kernel for the vent alignments of La Garrotxa.

where $\Delta x \Delta y$ is the size of the grid cell $(500 \mathrm{~m} \times 500 \mathrm{~m})$ and $\Lambda(x, y)$ is the weighted sum of the four PDFs and their relative weights.

QVAST provides two opportunities for assigning the weights that reflect the importance and reliability of each input data set. In the first, the user does not assign any specific individual weight and so QVAST defines the same constant value for all PDFs in the computation of the final probability map. In the second case, weights are assigned using expert judgment on the basis of structural criteria (Aspinall, 2006; Neri et al., 2008; Martí and Felpeto, 2010), which provides initial indicative probability distributions to be associated with each PDF.

In this case study, we demonstrated the flexibility of QVAST by generating two different susceptibility maps.

In the first map, the same weight (i.e., 0.25) was assigned to each PDF under the assumption that the probability of all future vent openings is influenced equally by all volcano structural data.

In the second case, we assigned to each of the PDFs the following weights for Lanzarote:

- 0.05 for dykes,

- 0.15 for the oldest vent alignments,

- 0.3 for the most recent vent alignments,

- 0.5 for the emission centers; and for La Garrotxa, the following weights:

-0.3 for the vent alignments,

- 0.7 for the emission centers.

On Lanzarote, the highest weight $(50 \%)$ was assigned to the emission centers in the center of the island, where eruptions occurred in historical times. This means that new eruptions are given the greatest likelihood of occurring close to the most recent eruptions. Decreasing importance was awarded to the most recent vent alignments, the oldest vent, alignments and dykes. Obviously, the total sum of weights is equal to 1 . In La Garrotxa, the highest weight (70\%) was assigned to the emission centers.

The two final susceptibility maps for Lanzarote are shown in Fig. 12 and for La Garrotxa in Fig. 13.

As it is obvious, on Lanzarote the susceptibility obtained using the same weight for all PDFs (Fig. 12a) provides a very homogeneous probability distribution, with the highest values corresponding to exposed dykes. This is disputable, since these dykes are volcanic structures that are clustered as a wide swarm chiefly at the headwalls of the main landslide and have probably been buried by recent volcanic products in other areas. Hence it is not clear whether they have acted as feeders or not (Becerril et al., 2013).

Conversely, the susceptibility map obtained using different weights (Fig. 12b) would appear to be more accurate and reliable, and reflects coherently the recent distribution of alignments located in the central part of the island in a NE-SW direction.

If we change the assigned weights, results differ for Lanzarote but not for La Garrotxa. In fact, in this latter volcanic field, the susceptibility maps obtained using the same (Fig. 13a) and different weights (Fig. 13b) for the PDFs are both coherent. The choice of the final technique for constructing hazard maps depends on the reliability of the method used to assign the weights.

\section{Conclusions}

The elaboration of a susceptibility map based on the quantification of objective geological and geophysical data is the first and most important step in the quantitative assessment of volcanic hazard and risk. Here we have presented QVAST, the new tool for calculating volcanic susceptibility that works under QGIS, a free and user-friendly GIS environment.

QVAST is built to evaluate volcanic susceptibility, that is, the spatial probability of the appearance of a future vent opening, based on the activity of the volcanic area under study. The main steps involved are as follows: (i) calculation of the bandwidth using different methods, (ii) evaluation of the PDF using a Gaussian kernel, (iii) assignment of the weights to each PDF, and (iv) evaluation of the susceptibility map using an NHPP. 

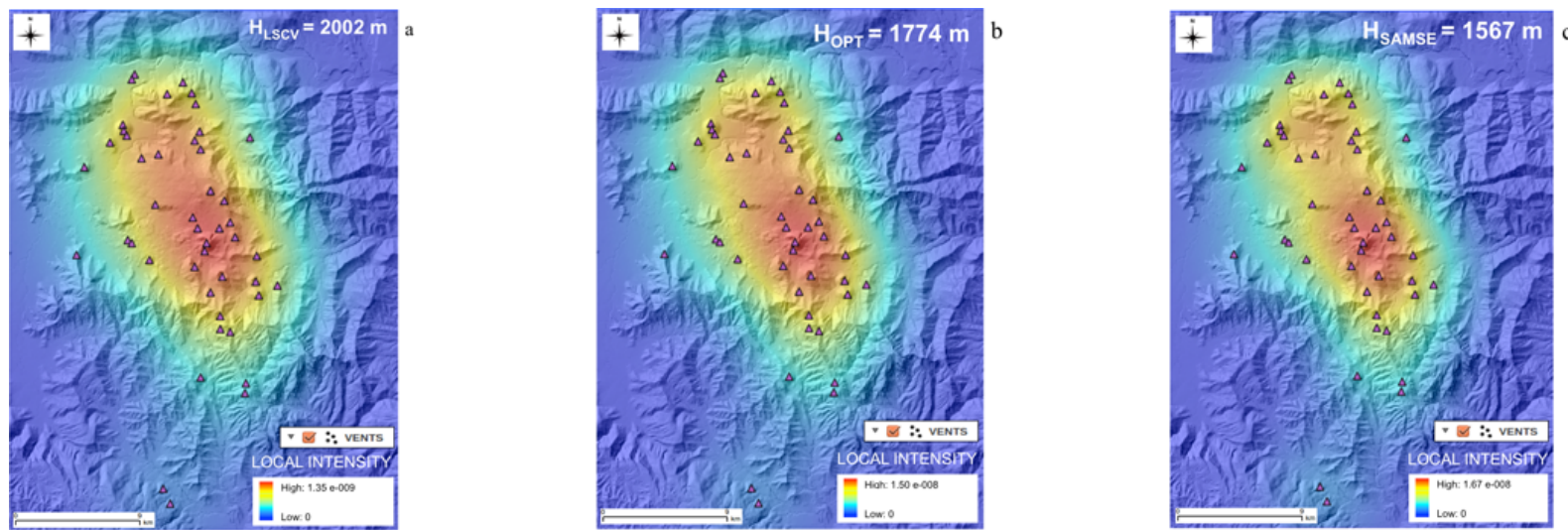

Fig. 11. PDFs of La Garrotxa emission centers calculated with the Gaussian kernel using different bandwidths: $2002 \mathrm{~m}$ as computed by the LSCV method (a), $1774 \mathrm{~m}$ as by the $h_{\text {opt }}$ score (b), and $1567 \mathrm{~m}$ as by the SAMSE selector (c).
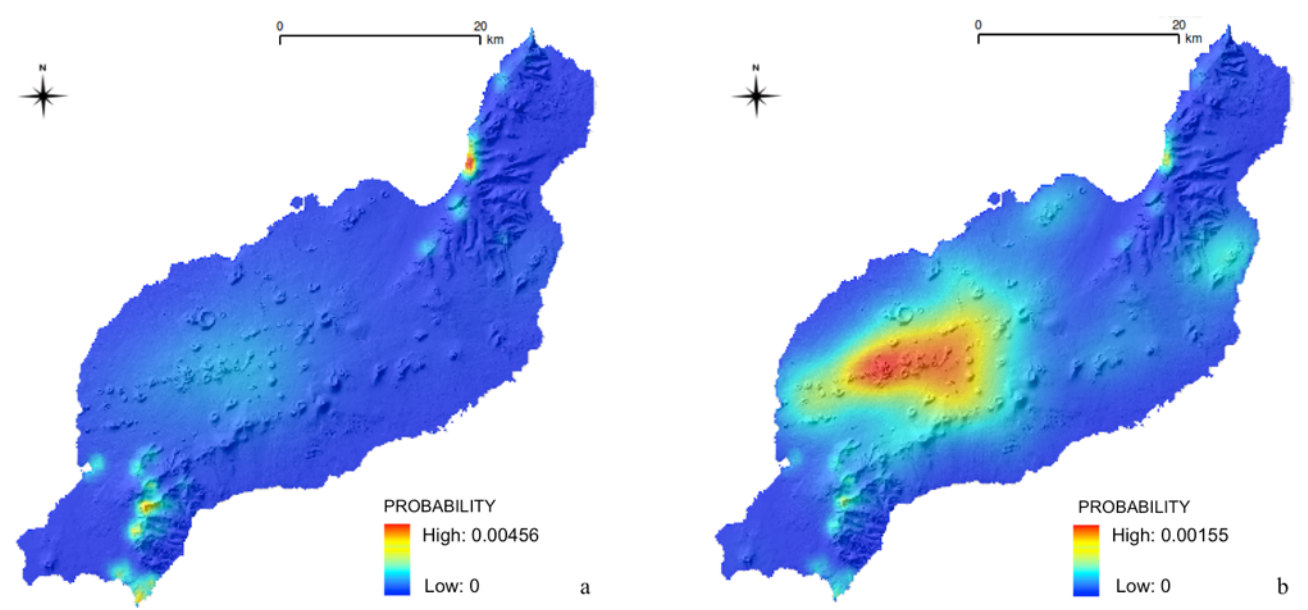

Fig. 12. Lanzarote susceptibility maps calculated assigning the same weights to all PDFs (a) and variable weights, i.e., 0.05 for dykes, 0.15 for the oldest vent alignments, 0.3 for the most recent vent alignments and 0.5 for the emission centers (b).
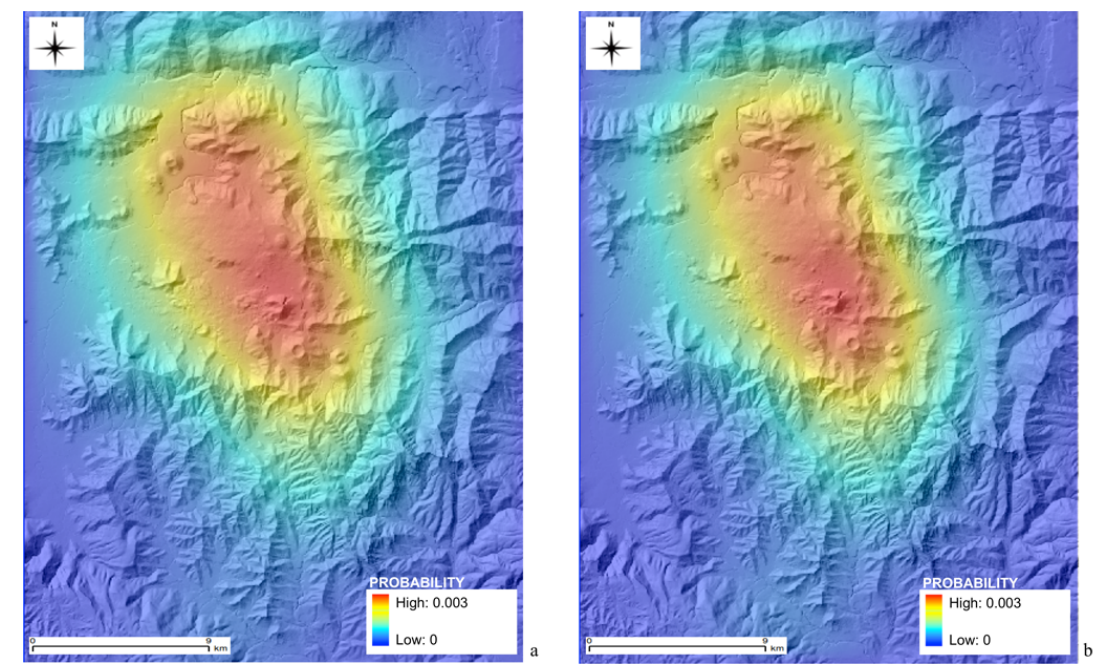

Fig. 13. La Garrotxa susceptibility maps calculated assigning the same weights to all PDFs (a) and variable weights, i.e., 0.03 for alignments and 0.7 for the emission centers (b). 
The comparison of different volcanic fields shows the importance of choosing the optimal bandwidth parameters. The strength of QVAST lies in the possibility of selecting various methods for evaluating the bandwidth parameter and for obtaining the final susceptibility map. The volcanic fields of Lanzarote and La Garrotxa are excellent case studies for learning how to use this interface and for comparing the different results generated using different bandwidths for the kernel; this thus allows an optimal bandwidth for the volcanic field to be chosen.

QVAST is part of a larger project consisting of several modules (implemented in QGIS) that will interact and will analyze the current situation of volcano fields as part of the task of generating hazard maps.

In the cases of Lanzarote and La Garrotxa, although data availability is somewhat restricted, the preliminary results obtained are good enough to be used as a starting point for generating eruptive scenarios that can aid local territorial planning and risk-mitigation programs. Thus, we propose that this tool should be used as a common way for determining the susceptibility of future volcanic eruptions in active regions and as a necessary tool in the reduction of volcanic risks.

Future work will include the spatiotemporal analysis of future vent openings and the construction of volcanic hazard maps, all of which will be of great help to the governmental bodies in charge of territorial planning and the development of mitigation plans.

Acknowledgements. This work was supported by the European Commission (FP7 Theme: ENV.2011.1.3.3-1; grant 282759: VUELCO) and developed in the frame of TecnoLab, the Laboratory for the Technological Advance in Volcano Geophysics organized by INGV-CT and UNICT. The authors thank Rosa Sobradelo, Erika Ronchin, and Elisabeth Riera Pedra for improving the paper. The English text was corrected by Michael Lockwood. We thank Olivier Jaquet and an anonymous reviewer for the supportive comments that helped to improve the manuscript, and the Editor Antonio Costa for his efficient handling.

Edited by: A. Costa

Reviewed by: O. Jaquet and one anonymous referee

\section{References}

Aspinall, W. P.: Structured elicitation of expert judgment for probabilistic hazard and risk assessment in volcanic eruptions, in: Statistics in Volcanology, edited by: Mader, H. M., Coles, S. G., Connor, C. B., and Connor, L. J., Geological Society of London, Special Publication of IAVCEI, 1, 15-30, 2006.

Banda, E., Dafiobeitia, J. J., Surifiach, E., and Ansorge, J.: Features of crustal structure under the Canary Islands, Earth Planet, Sci.Lett., 55, 11-24, 1981.

Becerril, L., Cappello, A., Galindo, I., Neri, M., and Del Negro, C.: Spatial probability distribution of future volcanic eruptions at El
Hierro Island (Canary Islands, Spain), J. Volcanol. Geoth. Res., 257, 21-30, doi:10.1016/j.jvolgeores.2013.03.005, 2013.

Blanco-Montenegro, I., Montesinos, F. G., García, A., Vieira, R., and Villalaín, J. J.: Paleomagnetic determinations on Lanzarote from magnetic and gravity anomalies: Implications for the early history of the Canary Islands, J. Geophys. Res. Solid Earth, 110, 1-12, doi:10.1029/2005JB003668, 2005.

Bowman, A. W.: An alternative Method of Cross Validation for the Smoothing of Density Estimates, Biometrika, 71, 353-360, 1984.

Camacho, A.G., Vieira, R., and Toro, C.: Microgravimetric model of the Las Cañadas caldera (Tenerife), J. Volcanol. Geother. Res., 47, 75-80, 1991.

Cappello, A., Vicari, A., and Del Negro, C.: Assessment and modeling of lava flow hazard on Etna volcano, Boll. Geofis. Teor. Appl., 52, 299-308, doi:10.4430/bgta0003, 2011 a.

Cappello, A., Vicari, A., and Del Negro, C.: Retrospective validation of a lava flow hazard map for Mount Etna volcano, Ann. Geophys., 54, 634-640, doi:10.4401/ag-5345, 2011 b.

Cappello, A., Neri, M., Acocella, V., Gallo, G., Vicari, A., and Del Negro, C.: Spatial vent opening probability map of Etna volcano (Sicily, Italy), Bull. Volcanol., 74, 2083-2094, doi:10.1007/s00445-012-0647-4, 2012.

Cappello, A., Bilotta, G., Neri, M., and Del Negro, C.: Probabilistic modeling of future volcanic eruptions at Mount Etna, J. Geophys. Res. Solid Earth, 118, 1-11, doi:10.1002/jgrb.50190, 2013.

Carracedo, J. C., Rodríguez Badiola, E., and Soler, V.: The 17301736 eruption of Lanzarote, Canary Islands: a long, highmagnitude basaltic fissure eruption, J. Volcanol. Geotherm. Res., 53, 239-250, 1992.

Chen, D., Shams, S., Carmona-Moreno, C., and Leone, A.: Assessment of open source gis software for water resources management in developing countries, J. Hydro-environ. Res., 4, 253264, 2010.

Coello, J., Cantagrel, J. M., Hernán, F., Fúster, J. M., Ibarrola, E., Ancochea, E., Casquet, C., Jamond, C., Díaz de Terán, J. R., and Cendrero, A.: Evolution of the eastern volcanic ridge of the Canary Islands based on new K-Ar data, J. Volcanol. Geotherm. Res., 53, 251-274, 1992.

Connor, C. B. and Hill, B. E.: Three nonhomogenous Poisson models for the probability of basaltic volcanism: application to the Yucca Mountain region, Nevada, J. Geophys. Res., 100, 1010710125, 1995.

Connor, L. J., Connor, C. B., Meliksetian, K., and Savov, I.: Probabilistic approach to modeling lava flow inundation: a lava flow hazard assessment for a nuclear facility in Armenia, J. Appl. Volcanol., 1, 1-19, doi:10.1186/2191-5040-1-3, 2012.

Diggle, P. J.: A kernel method for smoothing point process data, Applied Statistics, J. R. Stat. Soc. Ser. C, 34, 138-147, 1985.

Duong, T.: ks: Kernel Density Estimation and Kernel Discriminant Analysis for Multivariate Data in R, J. Stat. Soft., 21, 1-16, 2007.

Duong, T. and Hazelton, M.: Plug-in bandwidth matrices for bivariate kernel density estimation, J. Nonparametr. Stat., 15, 17-30, 2003.

Favalli, M., Tarquini, S., Papale, P., Fornaciai, A., and Boschi, E.: Lava flow hazard and risk at Mt. Cameroon volcano, Bull. Volcanol., 74, 423-439, doi:10.1007/s00445-011-0540-6, 2011. 
Felpeto, A., Araña, V., Ortiz, R., Astiz, M., and García, A.: Assessment and modelling of lava flow hazard on Lanzarote (Canary Islands), Nat. Hazards, 23, 247-257, 2001.

Felpeto, A., Martí, J., and Ortiz, R.: Automatic GIS-based system for volcanic hazard assessment, J. Volcanol. Geotherm. Res., 166, 106-116, 2007.

Gudmundsson, A.: Magma-chamber geometry, fluid transport, local stresses and rock behavior during collapse caldera formation, in: Caldera Volcanism, edited by: Gottsmann, J. and Marti, J., Developments in Volcanology, 10, Elsevier, Amsterdam, 313-349, 2008.

Gudmundsson, A.: Strengths and strain energies of volcanic edifices: implications for eruptions, collapse calderas, and landslides, Nat. Hazards Earth Syst. Sci., 12, 2241-2258, doi:10.5194/nhess-12-2241-2012, 2012.

Härdle, W., Müller, M., Sperlich, S., and Werwatz, A.: Nonparametric and Semiparametric Models, An Introduction, Springer Series in Statistics, Springer, Berlin, 2004.

Hornik, K.: The R FAQ, available at: http://CRAN.R-project.org/ doc/FAQ/R-FAQ.html, ISBN 3-900051-08-9, 2009.

Jaquet, O., Connor, C. B., and Connor, L.: Probabilistic Methodology for Long Term Assessment of Volcanic Hazards, IHLRMW, Las Vegas, USA, 2008.

Kiyosugi, K., Connor, C. B., Zhao, D., Connor, L. J., and Tanaka, K.: Relationships between temporal-spatial distribution of monogenetic volcanoes, crustal structure, and mantle velocity anomalies: An example from the Abu monogenetic volcano group, southwest Japan, Bull. Volcanol., 72, 331-340, doi:10.1007/s00445-009-0316-4, 2010.

Lutz, T. M. and Gutmann, J. T.: An improved method for determining and characterizing alignments of point-like features and its implications for the Pinacate volcanic field, Sonoran, Mexico, J. Geophys. Res., 100, 17659-17670, 1995.

Marinoni, L. B., and Pasquaré, G.: Tectonic evolution of the emergent part of a volcanic ocean island: Lanzarote, Canary Islands, Tectonophysics, 239, 111-135, 1994.

Martí, J. and Felpeto, A.: Methodology for the computation of volcanic susceptibility: Application to Tenerife Island (Canary Islands), J. Volcanol. Geother. Res., 195, 69-77, 2010.
Martí, J., Planagumà, L., Geyer, A., Canal, E., and Pedrazzi, D.: Complex interaction between Strombolian and phreatomagmatic eruptions in the Quaternary monogenetic volcanism of the Catalan Volcanic Zone (NE of Spain), J. Volcanol. Geotherm. Res., 201, 178-193, doi:10.1016/j.jvolgeores.2010.12.009, 2011.

Martí, J., Castro, A., Rodríguez, C., Costa, F., Carrasquilla, S., Pedreira, R., and Bolos, X.: Correlation of Magma Evolution and Geophysical Monitoring during the 2011-2012 El Hierro (Canary Islands) Submarine Eruption, J. Petrology, 54, 1349-1373, doi:10.1093/petrology/egt014, 2013.

Martin, A. J., Umeda, K., Connor, C. B., Weller, J. N., Zhao, D., and Takahashi, M.: Modeling long-term volcanic hazards through Bayesian inference: an example from the Tohuku volcanic arc Japan, J. Geophys. Res., 109, B10208, doi:10.1029/2004JB003201, 2004.

Neri, A., Aspinall, W. P., Cioni, R., Bertagnini, A., Baxter, P. J., Zuccaro, G., Andronico, D., Barsotti, S., Cole, P. D., Esposti Ongaro, T., Hincks, T. K., Macedonio, G., Papale, P., Rosi, M., Santacroce, R., and Woo, G.: Developing an Event Tree for probabilistic hazard and risk assessment at Vesuvius, J. Volcanol. Geotherm. Res., 178, 397-415, doi:10.1016/j.jvolgeores.2008.05.014, 2008.

Rudemo, M.: Empirical choice of histograms and kernel density estimators, Scandanavian J. Stat., 9, 65-78, 1982.

Scott, D. W.: On optimal and data-based histograms, Biometrika, 66, 605-610, 1979.

Scott, D. W.: Multivariate Density Estimation: Theory, Practice, and Visualization (Wiley Series in Probability and Statistics), Wiley Interscience Publications, ISBN-13: 978-0471547709, 1992.

Sherman, G. E.: Desktop GIS. Mapping our Planet with Open Source Tools, The Pragmatic Bookshelf, Raleigh, North Carolina, USA, 2008.

Silverman, B. W.: Density Estimation for Statistics and Data Analysis, Chapman \& Hall, London, 1986.

Weller, J. N., Martin, A. J., Connor, C. B., Connor, L. J., and Karakhanian, A.: Modelling the spatial distribution of volcanoes: an example from Armenia, in: Statistics in volcanology, edited by: Mader, H. M., Coles, S. G., Connor, C. B., and Connor, L. J., Spec. Pub. IAVCEI, Geol. Soc. London, 77-88, 2006.

Worton, B. J.: Using Monte Carlo simulation to evaluate kernelbased home range estimators, J. Wild. Manag., 59, 794-800, 1995. 